\title{
An exploration of designers' perspectives on human health and environmental impacts of interior textiles
}

\author{
Sage Calamari and Karen H. Hyllegard ${ }^{*}$
}

\begin{abstract}
Fast fashion and fast furnishings contribute to the unsustainability of the textile industry in multiple ways, and the deleterious impacts of fast furnishings, in particular, have encouraged some companies to embrace more holistic and sustainable approaches to interior textile design. As such, the purpose of this study was to explore designers' perspectives on if and how decisions made during the design process for interior textiles may impact human health and the environment throughout the product life cycle, and if and how these decisions may be influenced by the engagement with and/or responsibilities toward stakeholders. This research was informed by multiple frameworks, including the design for the environment (DfE), product life cycle assessment (LCA), and stakeholder theory. Data were collected using an interpretive, qualitative research method that involved in-depth interviews with 12 US designers/design managers who specialize in the development of residential and/or commercial interior textiles. Findings revealed that participants demonstrated professional understanding of human health and environmental issues during the preliminary stages of the life cycle, including raw material selection, textile fabrication, and finishes and treatments, whereas understanding of such issues at the later stages of the life cycle (packaging and transportation, consumer care, and post use) tended to be more theoretical rather than strategic. Findings also revealed differences among designers employed by DfE-oriented companies and designers employed at more conventional companies with respect to their apparent understanding of how decisions made during the design process may impact human health and the environment throughout the product life cycle. This research contributes to our understanding of the role that designers may play in mitigating the negative impacts of interior textiles throughout the product life cycle. A limitation of this study is the size of the sample; conclusions are based upon the insights gained from 12 designers of interior textile products, and thus may not be generalizable to all designers/companies in the residential and/or commercial interior textile industry.
\end{abstract}

\section{Background}

During the twentieth century, a manufacturing strategy known as planned obsolescence was implemented to encourage the design of products that decline in function or go out of fashion after a relatively short period of use (Whiteley 1987). Although products designed using a planned obsolescence strategy provide some economic benefits for the manufacturer, such products have the potential to negatively impact human health and the environment through all stages of their life cycle. For example, pesticides used during the cultivation of raw

\footnotetext{
* Correspondence: Karen.Hyllegard@colostate.edu

Department of Design and Merchandising, Colorado State University, 324 Gifford Bldg. (1574), Fort Collins, CO 80523-1574, USA
}

materials and chemical runoff during the manufacturing process have a direct, negative impact on the environment, which, in turn, may endanger the health of workers, community members, and consumers. Within the global textile and clothing industry, planned obsolescence is supported by growing consumer demand for luxury goods and a quick response manufacturing model (Niinim ki 2015). Planned obsolescence has become so commonplace in the industry over the last 20 years that the term fast fashion has been coined to specifically denote low-cost clothing that imitates luxury fashion trends and encourages disposability (Joy et al. 2012). More recently, the term fast furnishings has been applied to the design of low-cost home/soft furnishings, which 
similarly involves shortened cycles in the manufacturing, marketing, and consumption of residential and commercial interior textile products such as upholstery, window treatments, carpet/rugs, bedding, and decorative pillows, and likewise can have deleterious impacts on human health and the natural environment (Araji and Shakour 2013; Rastogi 2009; Wright et al. 2008).

The advent of fast fashion and fast furnishings contributes to the unsustainability of the textile industry in multiple ways, including the overuse of natural resources, escalating pollution/waste, the presence of toxins and carcinogens in fabrics, and the growing volume of clothing and textile goods that end up in landfills or incinerators (Birtwistle and Moore 2007; Jackson 2014; Whitehead 2014). It is the deleterious impacts of fast furnishings, in particular, that have encouraged some companies to embrace more holistic and sustainable approaches to interior textile design. One such approach-design for the environment (DfE) - is a design philosophy or process that considers the economic, health, and environmental impacts associated with a product across its life cycle and that emphasizes the use of safe and sustainable materials, features, and processes (Kim 2010; Fiksel 1996; Mackenzie 1991; Niinim ki 2006; Ramani et al. 2010; Sun et al. 2003; Yang et al. 2011). As such, the purpose of this study was to explore designers' understanding of, and consideration for, sustainability (or DfE) as it relates to the design and development of commercial and residential interior textiles. More specifically, the aim was to gain insight into designers' perspectives on if and how decisions made during the design process for interior textiles may impact human health and the environment throughout the product life cycle and if and how these decisions may be influenced by engagement with and/or responsibilities toward diverse stakeholder groups.

This study contributes to our understanding of the role that designers may play in mitigating the negative impacts generated by interior textiles throughout the product life cycle, which is important owing to the size and scope of the textile industry and its impact on human health and the environment. Driven by consumer demand worldwide, the value of the global textile industry (i.e., yarns, fabrics, and finishes) continues to rise and will reach $\$ 791$ billion (\$US) in 2016 (Lu 2015). Simultaneously, the industry has become one of the five largest contributors to $\mathrm{CO}_{2}$ emissions in the USA and an even larger contributor in the developing world (Dev 2009; Oecotextiles 2009). Research on the negative impacts of interior textiles has often focused on singular outcomes, such as contamination of indoor air quality attributed to such products (e.g., Coggon 1996; Ip et al. 2003; Tremblay et al. 1999).
Few studies have addressed the human health and environmental impacts generated by textile products across the product life cycle or how these impacts might be mitigated by the decisions made at the design stage of the product life cycle, including decisions to recycle and reuse materials. Further, most of these studies have focused on apparel products or specifically on textile dyes and other finishes (Gam et al. 2011; Pammi et al. 2012; Wright et al. 2008). Dissemination of findings from the present study may help to foster the integration of more sustainable practices in the production and consumption of interior textile products, which, in turn, will mitigate some of the negative impacts of these products on human health and the environment.

It is well documented that textile products generate deleterious human health and environmental impacts throughout the product life cycle, from raw material cultivation to the disposal of finished goods (Gam and Banning 2011; Gam et al. 2009; Giudice et al. 2005; Laitala and Boks 2012; Niinimäki and Hassi 2011; Stegall 2006). Such deleterious impacts often involve inputs and outcomes specific to chemical use, indoor air quality, and energy and water consumption. For example, the production of conventional cotton involves the use of large amounts of pesticides and insecticides, some of which remain in the finished textile product throughout its life cycle (Chen and Burns 2006). Additionally, textile production processes, such as scouring, dyeing, and finishing, are often performed with chemicals that are harmful to human health and the environment (Araji and Shakour 2013; Cobbing and Ruffinengo 2013; Thiry 2005). Chemical finishes and adhesives applied during the production stage (e.g., stain and flame retardants) may be released into the environment during the later stages of product consumption and disposal. For example, decabromodiphenyl ether (DecaBDE) is a hazardous chemical commonly used as a flame retardant finish for interior furnishings that can seep into the ground during its slow decomposition and thereby negatively impact the health of humans and wildlife (Tremblay et al. 1999; Wright et al. 2008). Despite the regulation of hazardous chemicals in the USA and Europe, much of the world's textile manufacturing has moved to countries where the environmental standards are less strict and hazardous chemicals are more likely to be used during production (Abreu et al. 2012; Niinimäki and Hassi 2011). The use of these chemicals can be harmful to workers who handle the fiber and fabrics during production (Cobbing and Ruffinengo 2013; Goldbach et al. 2003) as well as to community members who may be exposed to contaminated water supplies owing to the lack of proper water treatment facilities (Chen and Burns 2006; Cobbing and Ruffinengo 2013; Goldbach et al. 2003). Chemicals used in packaging textiles for transport 
also may pose health risks to the workers who apply the chemicals, unload the shipment, and remove the products for retail display (Cobbing and Ruffinengo 2013; Preisser et al. 2012). Additionally, the transportation of materials from one factory (or country) to another contributes to greenhouse gas emissions (Caniato et al. 2012). The use of potentially harmful chemicals during the laundering process (e.g., toxic chemicals in fabric softeners, dryer sheets, and dry cleaning solvents) further exacerbates the environmental impacts of interior textiles (Chen and Burns 2006; Hu 2012; Laitala et al. 2011). Lastly, the disposal of textile goods results in 15.1 million tons of waste in the US landfills annually (US Environmental Protection Agency 2015), which is of significant concern because as these textiles decompose, methane, a potent greenhouse gas, releases into the environment and dyes and other chemicals leach into the soil potentially harming humans and wildlife. Although textile reuse and recycling can be less harmful to the environment than the manufacturing of new products from raw materials (Woolridge et al. 2006), the Environmental Protection Agency reports that only $15 \%$ of all US textile waste (roughly $5 \%$ of total municipal waste), was recovered for recycling in 2013 (US Environmental Protection Agency 2015).

Another concern that arises during the use of interior textiles and fast furnishings is the negative impact on indoor air quality (Araji and Shakour 2013; Daisey et al. 2003; Tremblay et al. 1999). Studies examining interior spaces with high concentrations of furniture, such as schools and offices, have found that poor indoor air quality also can cause "sick building syndrome" a physical reaction to indoor air quality usually in the form of fatigue and respiratory problems (Jaakkola et al. 1999). Three key features of interior furnishings that contribute to sick building syndrome are chemicals contained in the materials, chemicals on the surface of materials, and the release of chemicals during the "gas phase" through product usage (Uhdea and Salthammer 2007). Contamination may occur over time as interior furnishings commonly "off-gas," that is, as they release chemicals into the indoor environment, in part, due to the chemical finishes applied during manufacturing (Jaakkola et al. 1999; Thiry 2005). Further, textile wall coverings and carpet can trap allergens such as mites and molds and may contain trace amounts of formaldehyde (Tremblay et al. 1999). In combination with poor ventilation or environmental changes (e.g., humidity), these contaminants can negatively impact human health (Jaakkola et al. 1999; Uhdea and Salthammer 2007).

The use of organic cotton in the production of textile goods mitigates the environmental impact some; however, the cultivation of organic cotton requires an enormous amount of water in comparison to other fibers, including conventionally grown cotton (Muthu et al. 2012). Similarly, desizing, scouring, bleaching, mercerising, dyeing, printing, and finishing during the textile manufacturing process requires vast amounts of water, and subsequently generates significant amounts of wastewater and the need for water recovery systems (Chen and Burns 2006). The growing demand for and overconsumption of textile products, and the amount of energy and water used to care for these products, further contribute to the aggregate impact on human health and the environment (Chen and Burns 2006; Hu 2012; Laitala and Boks 2012; Laitala et al. 2011; Saxce et al. 2012). Over the past 20 years, the increased number of inexpensive home furnishing retailers in the marketplace (e.g., IKEA, Home Goods) and the growing merchandise assortments in home furnishing found among mass merchandisers, such as Walmart and Target, has heightened consumer demand for fast furnishings. The production of these goods, including the transportation of raw materials and finished goods from one factory (or country) to another contributes to energy consumption (Caniato et al. 2012). In addition to the volume of textile production and consumption, the amount of energy and water used to care for interior textile products adds to the overall environmental impact of these products (Chen and Burns 2006; Hu 2012; Laitala et al. 2011).

\section{Conceptual framework}

This research was informed by scholarly conceptualizations of sustainable product design processes that incorporate principles of DfE, product life cycle assessment (LCA), and stakeholder theory (Freeman 1984). DfE is a term that was introduced in the 1990s to encourage environmental awareness and action related to a company's product development efforts (Fiksel 1996). Since that time, DfE has grown to embody a philosophy and practice that engages designers in the consideration and mitigation of the negative impacts that a product creates on human health and the environment (Fiksel 1996; Fuad-Luke 2009; Graedel and Allenby 1996; Kim 2010; Mackenzie 1991; Papanek 1995; Niinimäki 2006; Ramani et al. 2010; Stegall 2006). DfE requires designers or engineers to consider the environmental impact of the product development process across the product life cycle, with the understanding that environmental concerns need to be addressed during the initial design stage of the process (Billatos and Basaly 1997). To encourage a life cycle approach to product development, various guidelines and comprehensive models based upon DfE principles have been developed to reduce the environmental impacts caused by the product development process, as have systems or tools for evaluating the impact of finished products (see Billatos and Basaly 1997; Bras 1997; Fiksel 1996; Fuad-Luke 2002; 
Handfield et al. 2001; Kamide et al. 2013; Keoleian and Menerey 1993; Leal-Yepes 2013; Sun et al. 2003). Further, DfE principles tend to be implemented by large manufacturers that have the resources to engage in such efforts and the clout to require suppliers to comply with their efforts as well as by the establishment of international standards, such as International Standards Organization (ISO) 14000, that provide companies with specific tools for managing their environmental responsibilities (Bras 1997).

The notion that organizations have responsibilities toward society that go beyond their legal obligations and economic interests (Carroll 1991) has prompted researchers to explore social responsibility, sustainability, and related terms (e.g., ethical fashion) in the context of the global textiles and clothing industry. Although definitions for these terms vary somewhat, they all address the social, environmental, and economic well-being of multiple stakeholders and are often used interchangeably in the literature (Dickson and Eckman 2006; Joergens 2006; Niinimäki 2006; Niinimäki 2015). Stakeholder theory posits that businesses have distinct obligations and responsibilities toward multiple groups that may influence managerial decision-making, including decisions related to sustainability (Freeman 1984; Sun et al. 2003; Zakhem et al. 2008). Establishing long-term relationships with various stakeholders-employees, suppliers, competitors, governments, NGOs, consumers, and communities-can support efforts toward sustainability through the creation of new opportunities for businesses and greater value for stakeholders (Levi Strauss \& Co. 2015; Niinim ki 2015; Sun et al. 2003). Behrendt et al. (1997) explained that three levels of stakeholders are involved in the life cycle design, and each level is distinguished by the importance of the stakeholders' involvement. The first level includes company personnel, such as product designers and developers, product managers, sales and marketing managers, and environmental and safety experts. The second level of stakeholders includes external parties that support the product supply chain with respect to materials, production, packaging, distribution, etc. The third level includes customers, governments, stockholders, and environmental organizations. In the context of interior textile design, all levels of stakeholders may influence product life cycle and sustainability, including product designers/ developers, sales and marketing managers, production experts, fiber producers, textile mills, product finishers, third-party organizations, such as the ISO and the Global Organic Textile Standard (GOTS), government agencies, and clients or customers, as well as dry cleaners and product restorers/recyclers.

The environmentally responsible design process model developed by Handfield et al. (2001) and the environmental design criteria or product life cycle assessment model employed by Designtex specifically for interior textiles (Environmental Design 2013) served as the integrated conceptual framework for this study. Together, these models provided the basis for understanding how decisions made during the design process for interior textiles may impact human health and the environment throughout the product life cycle and how these decisions may be influenced by an organization's engagement with and/or responsibilities toward its stakeholders. Although multiple authors (e.g., Keoleian and Menerey 1993; Mackenzie 1991; Pahl and Beitz 1988) have contributed to our understanding of the conceptual design and design for the environment dating back to the late 1980s and early 1990s, Handfield et al.'s (2001) environmentally responsible design process model was employed in the present study because it incorporates a DfE orientation that was specially applied to a manufacturer of office furniture (a textile-related product category), and as such, it provided a context by which to explore the design process for interior textiles. The model is based upon three propositions about environmentally responsible or ecologically sustainable organizations (ESOs). First, designers are given environmental objectives and goals for product design. Second, ESOs employ systems to explicitly consider and measure environmental objectives or criteria at key points throughout the product design process. Third, ESOs integrate environmental considerations into the design process by measuring environmental outcomes and incorporating outcomes into strategic planning (Handfield et al. 2001).

The present study was informed by the second proposition, which focuses directly upon product design/development and the idea that environmental objectives or criteria can be encouraged and evaluated throughout the design process; it is explained as a five-step process: concept, product design, process design, package design, and product launch (Handfield et al. 2001). Pahl and Beitz (1988) characterized conceptual design as an integral part (i.e., primary phase) of the design process during which designers engage in abstract thinking to identify the essential problems and to achieve a principle solution (i.e., concept); referring to conceptual design as the part of the design process that "specifies the principle solution" (p. 159). Handfield et al. 2001 similarly described this step in the process as the point when designers engage in creative exploration to identify potential environmental problems and to develop DfE-oriented solutions. Product design involves decisions related to product specifications and may include raw material selection and end-of-life planning; for example, selecting materials that can easily be recycled (Handfield et al. 2001). Process design involves decisions related to the product manufacturing and assembly. This step addresses human health and 
environmental concerns associated with manufacturing facilities and may include management of wastewater and pollution. Package design involves decisions regarding how the finished product will be packed for shipping for both purposes of protection and presentation at retail and may include choosing materials that have little environmental impact, reducing the amount of materials use, and/or modifying the manner in which the product is transported. The final step in product design/development is product launch, which involves the evaluation of environmental outcomes using a variety of methods (e.g., established DfE assessment tools, LCA, sustainability or regulatory experts, and cost analyses).

As the research demonstrates, product life cycle assessment is essential to improving environmentally sustainable production, to reducing the cumulative impact of interior textiles on human health and the environment, and to supporting engagement with external stakeholders to further reduce such impacts (Caniato et al. 2012; Chiu and Chu 2012; Goldbach et al. 2003; Levi Strauss \& Co. 2015; Ramani et al. 2010; Sun et al. 2003). Building upon the concepts developed by McDonough and Braungart (2002), the Designtex model outlines a seven-stage interior textile product life cycle, as well as design criteria to be evaluated at each stage, that ensures a "closed loop" approach to interior textile design. This approach involves purposeful decision-making intended to divert resources from landfills and to create products that can be recycled or reused, either biologically (i.e., composting) or through remanufacturing (Environmental Design 2013).

The first stage in the Designtex closed-loop cycle is the selection of raw materials to be used in finished goods, and in order to minimize the negative impacts of finished goods, designers are encouraged to select materials that are renewable, recycled, and/or organic. The second stage of the textile product life cycle involves decisions related to fabric construction (e.g., weaving, knitting) and finishing as well as evaluation to ensure that products achieve closed loop qualities. The third stage, production, focuses on the methods and resources used to make products and involves efforts/decisions to minimize the use of energy and water as well as to reduce the waste that occurs during manufacturing. The fourth stage, application, is specific to interior textile products because it involves decisions related to textile applications and the assembly of finished products (i.e., methods and materials). For example, the selected method of textile application or product assembly (e.g., glued, sewn, stapled, or tacked) may dictate if and how the component parts may be recycled or reused. The fifth stage, useful life, refers to the purchase, use, and care of textiles. Designers may influence negative impacts at this stage of the product life cycle by designing multifaceted products (e.g., reversible pillow covers to lessen consumption or extend length of use) or by choosing through the selection of materials that can be cleaned using non-toxic detergents. The end-of-use stage refers to product post-use and disposal and often involves goods ending up in landfills or incinerators; however, designers can lessen the potential human health and/or environmental impacts at this stage by selecting materials that are biodegradable as well as avoiding finishes that may release harmful chemicals or residue during decomposition. The final stage, reutilization, involves the completion of the closedloop product life cycle. This stage includes efforts to repurpose products or components parts of products for the creation of new products, thereby extending the life of the original product or product part and averting the disposal of products in landfills.

\section{Methods}

An interpretive, qualitative research method was employed to explore how professional designers demonstrate the understanding of and consideration for the potential human health and environmental impacts of interior textile products throughout the product life cycle. In-depth interviews were conducted with 12 designers/design managers who specialize in the development of residential and/or commercial interior textiles.

To address the challenge of identifying a representative sample, multiple sampling frames were used to identify potential participants for this study. First, Internet websites and trade magazines dedicated to home furnishings and interiors were used to identify companies and designers engaged in the development of interior textiles. Second, trade organizations that list member companies on their websites and two textile certification organizations, GOTS and OEKO-TEX (both of which provide lists of textile companies that comply with their standards) also were used to identify potential participants. The sampling frames produced a list of 50 US companies that met the criteria for inclusion (i.e., companies that employed an internal design team and did not sell materials that were designed out-of-house). Multiple attempts (via e-mail and telephone) were made to contact each company and to invite a design professional to participate in the study. Design professionals from 12 companies agreed to participate in the study. Representatives from three companies originally agreed to participate and scheduled interview times but later canceled and did not reschedule their interviews. Representatives from two companies declined to participate in the study citing time constraints or lack of interest. Thirty-three companies did not respond to multiple invitations to participate in the study; resulting in a final response rate of $24 \%$. Given the limited number of participants in this 
study, findings may not be representative of, or generalizable, to all designers/companies in the residential and/or commercial interior textile industry.

All 12 participants were employed by US companies, and their experiences varied somewhat with respect to job titles, professional backgrounds, and years in the textile design industry. Participants' professional titles included company owners, creative directors, design managers, and design assistants, and individual experience in the interior textile industry ranged from 1 to 40 years. At the time of data collection, participants played an integral role in, or had direct influence upon, the design and development of interior textile products. Participants were recruited through company websites, trade magazines, trade organizations, and industry certification organizations. The companies represented in this study ranged from small wholesale businesses to large contract corporations. Products developed by these companies included general use textiles, contract textiles, furniture, and home goods (i.e., bedding, tablecloths). Six of the companies demonstrated a DfE approach to the development of interior textile products.

An introductory e-mail with an attached cover letter explaining the purpose of the research was sent to each textile designer inviting him/her to take part in the study. Upon response to the e-mail and consent to take part in the study, each designer was asked to provide written responses (via e-mail) to questions pertaining to his/her educational background, years of experience in interior textile design, and current employment position. In-depth, semi-structured telephone interviews (30-80 $\mathrm{min}$ in duration) were then conducted with each participant to obtain information about the processes undertaken to design and develop interior textile products. Open-ended questions were used to best "capture the nature and meaning of creative experience from the perspective of the research participants themselves" (Mace 1997, p. 226). Example interview questions included, "How would you describe the general steps you take, from start to finish, to design a product?," "What sustainable practices are incorporated at your company related to product design and development?," and "What tools/aids/incentives are used to facilitate the consideration of sustainability concerns in the design process?" (see Additional file 1 for the complete interview schedule).

Interviews were audio-recorded, and participants' responses to the interview questions were transcribed verbatim, resulting in three forms of data-written responses to questionnaire items, written transcriptions of audio-taped interviews, and the primary researcher's handwritten notes. Upon completion of the data collection, written transcriptions and notes were read and organized through thematic analysis (Shank 2002). A constant comparison approach was used to systematically code, categorize, and compare the data throughout the analysis process (Glaser and Strauss 1967; Glesne 2011; Strauss and Corbin 1998). Notes taken during the initial reading of each transcribed interview helped to isolate important fragments of text or units of meaning and to identify key concepts and categories in the data (Guetzkow 1950), which were then used to establish a coding guide that was applied to all 12 interviews. As data analysis progressed using the established coding guide, themes in the narratives were identified and compared across the transcripts. An audit coder checked the researcher's application of the coding guide to ensure accuracy and consistency in the data analysis. When disagreements occurred relative to the coding of the data, differences in coding were negotiated until agreement was achieved.

\section{Results and discussion}

The designer's narratives provided insight into their understanding of and consideration for the potential human health and environmental impacts of interior textiles throughout the product life cycle. Content analysis of these designers' narratives on the topic of sustainability (or DfE) as it relates to the design and development of commercial and residential interior textiles revealed six themes that coalesce around the stages of the product life cycle: raw material selection; textile fabrication; textile finishes and treatments; product packaging and transportation; consumer purchase, use, and care; and post-consumer use. The designers' narratives also revealed how engagement with and/or responsibilities toward stakeholders supported their efforts toward creating sustainable interior textile products.

\section{Raw material selection}

Material selection, specifically choice of fibers, was a common theme in the designer's narratives on product design for interior textiles. When discussing material selection, multiple designers expressed concerns regarding the human health and environmental impacts of interior textiles, although such concerns were not usually the primary or singular factor in their decision-making. For example, one participant explained that the decision to use natural and/or synthetic fibers in interior textiles involved environmental considerations as well as esthetic or performance characteristics (i.e., drape):

I found a completely recycled fabric...50\% organic cotton, $30 \%$ organic hemp and some recycled polyester. There are a lot of folks who feel differently about polyester...but I knew having some polyester in the fabric was going to help as far as draping...So I 
folded it and tested it and looked at how it would drape. (Participant 1)

For this designer, the selection of a material constructed from organic fibers and recycled polyester presented an ideal compromise because the desired esthetic or performance is achieved with minimal environmental impact, specifically through the reuse of waste material through recycling. DfE designers participating in this study also expressed the idea that, at times, esthetic or performance needs may limit the selection of sustainable raw materials, as conveyed in the following quote:

If we're looking at a colorful panel, but we need to do it in a recycled polyester...but then a post-industrial recycled polyester doesn't take color as well as a post-consumer recycled [polyester] might, so it might deter us from using that yarn because we cannot get the colors we want. (Participant 6)

This quote suggests that options for recycled raw materials within the DfE framework may be influenced by original product use (i.e., industrial vs. consumer); however, this opinion on esthetic quality may have been influenced strictly by the designer's individual experience. The performance qualities of post-industrial and postconsumer recycled materials cannot be generalized because the esthetic quality of the color would likely be dependent upon the specific material and the specific dye technique. Another participant noted an esthetic concern with respect to printing on blended fibers.

Because of the recycled (polyester) content in combination with the natural (fiber) content, you get a lot of variation in the color of the fibers and you also get a lot of little slugs in the fibers and because it's only surface printing...if a little slug is raised then there is no printing there. (Participant 1)

This designer experienced difficulty with both the color consistency and the surface quality of a base cloth due to the fiber choice. The concern evident in this quote is the impact the fiber choice may have on the final product, especially when using a surface printing method.

The designers' narratives demonstrated a rich understanding of the potential human health and environmental impacts of selected raw materials. When speaking about a textile wall covering, one participant provided a more comprehensive explanation for material selection, stating that it "had a really nice sustainability profile, good recycle content, it didn't contain PVC [polyvinyl chloride], POAs [polyalphaolefins] or any harsh chemicals, very low VOC [volatile organic compound] emissions" (participant 1). Designers also conveyed understanding of how material selection may diminish the human health and environmental impacts of interior textiles at later stages of the product life cycle. One participant stated that material selection was directly influenced by fiber decomposition at the end-of-life stage of the product life cycle:

The materials I've chosen to use are kinds of materials that literally can be put into a landfill and biodegrade, they're not just sitting there forever. (Participant 5)

In order to reduce the amount of product that ends up in landfills at the end-of-life stage of the product life cycle, this designer chose materials that would be decomposed by bacteria or other living organisms.

\section{Textile fabrication: weaving, printing and dyeing}

A second theme of discussion was textile fabrication, which involves decisions related to weaving, printing, and dyeing processes. The designers' narratives revealed that textile fabrication methods are selected for a variety of reasons, including market demand; preferences or requirements for esthetics, pattern design, and quality; a designer's experience with various processes, and environmental impacts. Six of the participants represented companies that strictly design woven textiles, whereas the other six represented companies that engage in the design of printed textiles, or both woven and printed textiles.

With respect to textile fabrication, participants addressed the direct relationship between human health and environmental impact when discussing digital printing only. Two DfE-oriented designers specifically noted an environmental benefit of using digital textile printing technology because, unlike screen printing, which requires cutting large screens based on each design, a digital printer can quickly translate and produce patterns with little labor and less fabric for testing. As such, smaller yardage minimums are required for digital printing production and designers are able to print small runs of their fabrics to sell according to demand, thus reducing the potential for waste in the form of unused fabric.

Although most participants were not directly involved in the selection of textile dyes used in the printing processes, four participants explicitly noted the role of dye and print professionals in improving product sustainability, stating that they deliberately opted to work with textile mills that used "environmentally" or "water-based" dyes. For example, when asked about the criteria for choosing a textile printer, one designer stated "it's all water based (dyes), not solvent based so it still fits my parameters of being sustainable and eco" (participant 5). Another designer, who worked in a screen print facility and was directly involved in dye decisions, explained 
that water-based dyes are less toxic than other dyes, but noted that water-based dyes may include additives to improve the performance (e.g., colorfastness, stain resistance) of the finished product:

Our pigments are water based and low tox[icity]... base products are essentially a binder, a thickener and our base pigment, our saturated base pigment, and there are other variable elements...let's just call them, for lack of a better word-chemicals, that you would add to things to [create] different properties maybe, you add another additive when you print on an already treated material and that helps it suck into the fiber which is kind of like rubbing alcohol. You might add a mildew [resistant] or UV [protectant] additive so the pigment lasts longer in direct sunlight. For most pigments you typically don't add any of those things, it's water, it's a binder, it's a thickener and a base color. (Participant 7)

This quote demonstrates the variety of components that may be integrated into a dye as well as the potential for additives to be integrated early in the life cycle of the textile product, including into dyes that are considered to be less harmful to human health and the environment.

When discussing textile fabrication/product manufacturing, multiple participants addressed their partnerships with a key stakeholder group-textile mills and/or production factories. As noted by one participant, decisions to work with mills or factories were often based upon a shared commitment to the environment:

From a conscious level of being a provider of textiles we make sure that mills are behaving properly and that's also on how they deal with their water, their dyes, their machinery and down to are they using recycled boxes. (Participant 4 )

This quote conveys the textile company's holistic sense of responsibility to ensuring that production practices-all the way through to product packaging methods-at the mills they choose to work with are aligned with their own company's values. Another participant, who works for a company that utilizes US manufacturing, touched on the difficulty of finding partners overseas that share the company's values:

As of now we have not done anything in Asia, it's not out of the question we just haven't

found the right partner, there's a lot of things we don't agree with when we try to do business out there. (Participant 6)
When discussing textile fabrication, participants frequently addressed partnerships with NGOs, specifically third-party organizations, such as the Association of Contract Textiles (ACT), the GOTS, and the ISO, which provide standards, testing, certification for textiles, and/ or monitoring of environmental and social records for mills. Multiple participants cited third-party organizations, including factory monitors/inspectors, as important stakeholders in their efforts to minimize the human health and environmental impacts of interior textile products. For example, the ISO's production standards and certifications can be used to assess factory performance related to working conditions and environmental impacts:

In all honesty in my opinion within the world of textiles, whether it's clothing or textiles it's not a very environmental idea, the dyes into yarn, you're getting into factors that are not necessarily great for the environment. And I will not stand here and say to you that I am fully versed in environmental aspects of products. What I can tell you is that every mill that we work with goes through a very strong background check from us in terms of being ISO 9000 certified, I believe is the number [for clarification, ISO 14000 and 26000 are the numbers currently used by the ISO], and everyone is on board in terms of their practices, what happens in their mills, water consumption, recyclability, how they treat their employees. When we work with mills overseas like India, do they have the proper work environment? All of that is signed off on. (Participant 4)

As another participant noted, partnering with third parties provides a greater level of assurance with respect to the human and environmental impacts of production:

The (fabrics) are coming from a company that focuses on how the workers are treated, how the fibers are being grown, all those kinds of things, but to a certain degree you have to rely on third-parties for those things. (Participant 1)

Explicit in these quotes is the reliance that these designers place upon NGOs in evaluating and monitoring factory performance in support of sustainable textile production.

With respect to the third-party standards employed by their own companies, participants' narratives also revealed some limitations in the scope of current human health and environmental standards and certifications: 
It's hemp that I focus on, you know you can't even get hemp certified it's just not in the parameters [of GOTS]. (Participant 5)

The suggestion here is that some companies might be engaged in sustainable practices but do not engage in the third-party certification or labeling owing to the fact that not all materials or processes are addressed within third-party standards. Further, it is implied that NGOs could play an even greater role in advancing the development and production of sustainable interior textile products by expanding the scope of their certifications or regulations. One participant specifically noted that his/her company worked to achieve higher standards than those addressed in third-party certifications:

We look at third-party certifications as a bench mark of where we want to go from, we're really trying to do better than to just hit that [benchmark]. (Participant 6)

Although organizations such as ACT offer sustainability tools (e.g., checklists and certifications), some compliant companies may rely more on self monitoring and, thus, may be incorporating sustainable practices that exceed third-party standards. Also, the general lack of enforcement of such standards was noted as problematic with respect to how products are marketed:

What I believe would help is more accountability...I think there should be a third-party team...(that) would actually do something when people don't do what they say they're doing, putting things out there like vinyl which is a proven human carcinogen and putting it next to green vinyl or recycled vinyl. (Participant 6)

This quote highlights the lack of oversight and authority among NGOs to prevent "greenwashing." This may, in part, be attributed to the voluntary nature of partnering with an NGO such as GOTS, wherein the NGO only has the authority to certify a company that requests certification. Further, for voluntary certifications such as GOTS, the only discipline a company may face for noncompliance is the removal of the certification label.

Another participant alluded to the magnitude of factors that need to be considered when attempting to assess sustainability and the need for comprehensive evaluation system or tool would benefit product designers/developers, mills, and consumers:

Years down the road [sustainability] might be something that is more strictly enforced and be a standard...because there are so many different aspects, there are thousands (of) different aspects that make one textile look really
environmental...I think having that tool simplifies it for not only the mill but the developers...the consumers so they really know what they're buying and having it simple and comprehensive. (Participant 8)

\section{Finishes and treatments}

The third theme identified through content analysis was textile finishes and treatments. Although textiles can be treated at different points throughout the weaving and printing processes, a majority of the participants addressed finishes that were applied after the textile is manufactured. The designers explained that chemical finishes are applied to the textiles for a variety of reasons including, but not limited to, industry imposed standards (i.e., flame-retardant, antimicrobial) and market demands related to performance (i.e., UV protection, stain resistance). One participant explained that contract textiles-textiles used in hospitals, offices, and schools-need to be high-performance materials meaning that they need to be more durable, to withstand cleaning by harsher chemicals, and to follow state and federal guidelines for safety:

We choose finishes based on the market that we want to go after...for instance, we have a textile coming out we want to market towards a higher education application and hospitality, both of those fields look for high abrasion results and for stain resistance, and kind of bigger, more hefty [fabrics]. It's probably not going to get a lot of wear so we probably won't finish it at all. (Participant 8)

Three DfE-oriented designers also discussed the importance of exploring nanotechnology, the science of modifying the fiber on a molecular level to increase performance, as an alternative to chemical finishes. Although these designers seem to suggest that the application of nanotechnology to textiles may reduce negative impacts, it should be acknowledged that the full human health and environmental impacts of nanomaterials are unknown (i.e., understudied) at this time (Nanotechnology textiles 2010; Rivera, Seely, and Sutherland 2012). Almost all of the participants, however, acknowledged that the healthiest textiles are the ones without any finish treatment:

We are really big believers in no finish is the best finish...there are many finishes that won't allow bacteria to grow, but then the finish is bad for the environment, bad for you to inhale so we don't go that route. (Participant 6)

This participant's position demonstrates the dilemma associated with the use of some chemical treatments, 
which is that although a finish may eliminate one problem, such as bacteria, it also may create other health and environmental problems. Another participant echoed the notion that the "greenest" approach is to avoid the use of finishes altogether, and explained how one stakeholder group-customers' concerns over finishes at the consumption stage of the product life cycle-influenced the company's decisions related to its product assortment:

A few companies offer greener options as far as finishes...but the greenest way to finish a fabric honestly is not to finish it at all. And it really comes down to the market, for instance, in California, a lot of people won't use fabrics that have any finishes so we do warehouse a few of our popular fabrics that come with a standard finish, [or] without a finish.

(Participant 8)

\section{Packaging and transportation}

Product packaging and transportation also was a theme in the participating designers' narratives on interior textile products. More than half of the participants indicated that their companies sourced materials or manufactured component parts of the textile product through mills in the USA, Europe, and/or Asia. When discussing issues of waste, cost, carbon footprint, and chemicals related to sourcing and production, all participants expressed the desire to reduce the negative impacts of packaging and transportation. However, the designers implied that the ways in which products are packed and shipped were outside their personal control/responsibility, either because the product was packaged at the mill or because it was handled by another department in their company. One participant expressed awareness of package waste but also implied that the amount of waste could only be determined at the end of the transportation chain and that the responsibility for how things are packed was in the hands of another employee:

Some of our rugs, they're in a bag inside a bag, inside a bag, and then we re-bag them. It's something our warehouse manager has been looking at, but it takes looking at something after a container comes in and broken down and product put on shelves, the amount of waste is a lot. (Participant 10)

Another participant demonstrated a holistic approach to using environmentally sensitive materials for daily operations, including business communications and product packaging:

I print all my [letter] head on it (hemp paper), I print my business cards on it, I use recycled brown tissue paper and recycled brown pages for my products...I use recycled paper from [name omitted] if I'm sending pages and pages of my eco data to someone. (Participant 5)

The participants also tended to view the method of transportation as outside the scope of their control or responsibility. One participant, however, addressed transportation issues in a comparison of carbon footprints when sourcing cotton fabric in India versus the USA:

Three or four years ago I tried to analyze the carbon footprint of India vs. U.S. production ...in the United States the fabric was bouncing around from so many different locations [but it's] fully vertical in India. The footprint in India was much larger, but not as drastic as you would think. Trucking [U.S.] is so much more carbon intensive than boat, which is how the fabric gets to us [from India], by boat and then by train. (Participant 3)

The implication here is that US sourcing, which often involves horizontally integrated production (i.e., weaving, dyeing, and finishing occurring at separate locations), compared to vertically integrated production in another country may generate a larger negative environmental impact during the production and distribution stages of the product life cycle owing to greater reliance on truck transportation throughout the production processes. A study conducted by the US Environmental Protection Agency (2013) indicating that heavy-duty trucks account for $22 \%$, aircraft accounts for $8 \%$, and boats account for only $3 \%$ of the greenhouse gas emissions produced by the transportation sector lends some support to this implication.

Another concern at the transportation phase of the interior textile life cycle was the use of chemicals to protect freight while being shipped. One participant claimed that formaldehyde is frequently used in containers shipped from countries such as China and India:

I don't care if it was organic in India or organic in China because it has then been sprayed with formaldehyde when it's brought into this country so it's really no longer organic and that is a really amazing awareness to have, especially when the marketplace advertised this as such desired quality...in essence unless it's been flown in, that's the only thing that prevents it from being sprayed with formaldehyde...that element is very important because on top of the carbon footprint, which is huge because you're shipping something from another country, you're also exposing it to formaldehyde which negates the organic element. (Participant 7) 
Research suggests that fumigants are used in shipping containers and can be harmful to the health of workers, even those who handle clothing; however, the claim specific to organic textiles is not addressed in the current research (Preisser et al. 2012). This quote raises yet another issue regarding the human health and environmental impact resulting from the selected method of product transport, specifically the potentially harmful chemicals or other substances that fabrics or products might be exposed to during this phase. This participant's account of chemical use at the transport stage suggests that exposure to chemicals influences human health and the organic nature of a product, and, therefore, textiles should only be air freighted when sourced internationally. Further implied is that what happens during the transportation stage should be transparent to the consumer, in particular, for credibility of an organic-labeled product.

\section{Consumer purchase, use, and care}

The designers' narratives with respect to creating more sustainable interior textiles also addressed consumer purchase, use, and care and included observations about consumer demand, knowledge, and education related to interior textiles. Although the market for sustainable textile products appears to be relatively small, analysis revealed a shared perception among participants regarding an increase in consumer demand for, as well as a growing availability of, DfE products and materials over time. As the following quote implies, consumers are playing an increasingly important stakeholder role in the advancement of sustainable interior textiles:

There's more organic cotton, more choices in construction of weaves, because customers are asking for it, even interior designers ask for it. I'm amazed that they say "I'm coming in because you're offering an eco-fabric and I can't find it around here". I never heard that when I started out, they were like "What does it mean? I thought organics were only in food." (Participant 5)

These designers also perceived an increase in consumer demand for information about or knowledge of the potential human health and environmental impacts of the textile manufacturing processes:

The textile supply chain is a fairly deep and long one and accessing data from far upstream has become more important to our end customers, there's a lot of demand for transparency whether that be around issues of ...how employees are treated...chemical inputs and their potential health hazard, it could be related to energy and carbon aspect. (Participant 11)
This observation suggests that consumers are developing a more sophisticated understanding of the textile product supply chain that may, in turn, inform a more holistic assessment of the potential human health and environmental impacts throughout the product life cycle among designers and consumers alike.

The participants also noted an increase in consumer knowledge of issues surrounding the production of sustainable textiles; however, four participants addressed the need to further educate consumers about the human health and environmental impacts of interior textile products. One participant specifically noted the need to educate consumers about the issue of off-gassing and poor indoor air quality, which can occur in the home environment through the use of glues and stain-resistant finishes on carpeting, upholstered furniture, and other textile products:

You have the whole process of educating people on... bringing materials into your home that may be offgassing and how much time they spend inside. (Participant 1)

Another participant expressed the importance of consumer education in the context of DfE-oriented design and specifically, and explicitly, addressed the designers' role as educators:

I think my calling is probably education and doing more on that because I think what's really missing is that the consumer doesn't understand why it (sustainability) is important and unless somebody tells that story they're not really going to know.

(Participant 3)

The implication here is that education about the importance of sustainability would likely be understood and well received if it was provided in a manner (i.e., story) that is relevant to the consumer. The designers' narratives also conveyed a shared role and responsibility for educating consumers-for providing the information and knowledge needed so that consumers may make fully informed choices relative to the selection of more sustainable interior textile products.

Multiple participants addressed the potential impacts of interior textiles during the use phase of the textile product life cycle, including concerns related to chemicals in the home, indoor air quality, and off-gassing. When addressing the question of sustainability in relation to interior textile product use, one participant specifically noted human health impacts: 
It's (about) making something that lasts that isn't going to affect us in any harmful way, leaching chemicals or off-gassing in my case. (Participant 5)

This participant's use of the word "my" implies a sense of personal responsibility to create products that will not negatively impact consumers' health.

Participants' narratives also addressed the issue of how consumers care for interior textile products. The majority of participants stated that they provide care recommendations for their products, and as demonstrated in the following quote, these recommendations often involved environmental considerations:

We have washing instructions on our site which is basically using environmentally [friendly] detergent and hang dry when you can, all of our fabric can be put in the dryer but for environmental reasons we recommend hang dry. (Participant 3)

Such recommendations may encourage consumers to embrace product care methods that will minimize the environmental impacts inherent in the laundering process, thereby engaging stakeholders in a company effort to improve the sustainability of interior textile products.

The designers' narratives further revealed that multiple stakeholders may play a role in informing the establishment of textile care instructions to minimize environmental impacts:

I recommend that [customers] use an environmentally friendly dry cleaner and...my drapery guy...doesn't even recommend you have your draperies dry cleaned unless you are a smoker, or unless you have animals or unless you have a lot of pollutants in the air that will damage the product. But I also tested the product to see if it would machine wash and go through those steps to try to figure out what I say about this product, a lot of people look at specifications, some don't. (Participant 1)

\section{Post-consumer use}

The final theme revealed in participants' accounts was post-consumer use, which was discussed in terms of product longevity, consumer waste, and product return programs. As might be expected, participants' discussions of post-consumer use emphasized the consumer as a key stakeholder at this stage of the product life cycle. Two designers described their products as timeless and expressed the hope that their products would never be disposed of, but rather might be given a second life; an idea that is conveyed in the following quote:
The U.S. consumer is really, really wasteful and, again, it's something in our company, we want to make things that you're going to pass down, we don't sell products that you're going to throw away (Participant 10).

Explicit here is a commitment to product longevity-producing products that will last for a long time and that may be passed down through generations and therefore used and cared for in a treasured manner. Similarly, one participant discussed disassembly as a way by which to make the product last longer:

If they [the furniture] need to be laundered or cleaned they can be dissembled, I kind of have my eye on archival concerns, because I want my work to last as long as it can...I want it to totally be cleanable so like most upholstered furniture, you can remove the fabric and clean it. (Participant 2)

This designer recognizes the role of consumer care in creating a more sustainable product. Disassembling a piece of furniture to clean the textile is a DfE strategy and contradictory to the notion of fast furnishing, which encourages consumers to discard furniture pieces when they appear dirty and used.

Multiple participants also discussed product longevity as a means by which to reduce overconsumption and waste, using consumer demand for fast fashion to illustrate the point:

Nobody buys clothing anymore to sit in your closet for ten years, they buy it and get rid of it. Think about what that does for the environment, because they can buy for $\$ 10$ versus investing in something that will last a long time. (Participant 4)

The suggestion here is that consumers can help to lessen the environmental impact of textile and clothing products by buying better quality products that last longer.

Upcycling, the reuse of materials at the post-use stage of the life cycle, as a strategy for waste reduction was not specifically mentioned by any participants; however, one participant did address a company-operated textile product return program as an alternative to post use disposal:

We have a responsible return program, you can send it back and it will get burnt down and made into energy or something else in the polypropylene line. (Participant 6)

In this program, a used textile may be manipulated in one of two ways-by creating energy utilized during 
textile manufacturing or by reusing the material to create fibers for a new textile. A product return program of this type suggests value in building a companyconsumer partnership to encourage the return (rather than the discard) of products after use, again helping to lessen the environmental impact of interior textile products.

Another designer focused the discussion of post-use strategies on creating new raw materials, the last step of a closed-loop life cycle:

Our guiding principle of sustainability [is] that things should either be technical nutrients, you know traveling through a technical cycle or a repeatable technical cycle, or biological nutrients where that product can go back through, can be biodegraded and contribute to compost to feed the next generation of wool and ramie for the [new] product. (Participant 12)

This designer isolated two different post-use strategies based upon type of material-inorganic vs. organic (McDonough and Braungart 2002). As this designer pointed out, inorganic materials may be placed within a "repeatable cycle" (e.g., reuse or recycling), an approach that may reduce the need to grow or manufacture new raw materials; whereas an organic compound may contribute to the growth of a new natural fiber.

\section{Conclusions}

Findings from this study provide insight into participating designers' perspectives on sustainability with respect to the design and development of commercial and residential interior textiles. More specifically, findings provide insights into these designers' understanding of and consideration for how decisions made during the design process for interior textiles may impact human health and the environment throughout the product life cycle and how these decisions may be influenced by an organization's engagement with and/or responsibilities toward its stakeholders.

Content analysis revealed that all participants in this study demonstrated knowledge of issues pertaining to the human health and environmental impact of interior textiles at various stages of the product life cycle. Most notably, participants demonstrated considerable understanding of human health and environmental issues during the preliminary stages of the life cycle, including raw material selection, textile fabrication, and finishes and treatments. This finding differs from that of Handfield et al. (2001) who concluded that designers relied on environmental experts for information and demonstrated very little knowledge of human health and environmental issues as related to their process. One possible reason for this difference may be that the technological and social changes of the last 10 to 15 years have given rise to greater awareness of sustainability issues, specifically in the textile sector.

Although all participants demonstrated knowledge with respect to the first three stages of the life cycle, discussions regarding human health and environmental impacts at the later stages of the life cycle (packaging and transportation, consumer care, and post-use) tended to be more theoretical rather than strategic in nature and in some cases issues were perceived to be out of the designer's realm of decision-making. Further, participants did not directly address human health and environmental impacts in relation to the application stage of the life cycle, even though this stage has been isolated as an important stage in the interior textile product life cycle based upon the Designtex environmental design criteria (Environmental Design 2013).

Findings also revealed differences among the designers employed by DfE-oriented companies and the designers employed at more conventional companies with respect to their apparent understanding of how decisions made during the design process may impact human health and the environment throughout the product life cycle. The designers employed by DfE-oriented companies expressed more concerns over the human health and environmental impacts of interior textile products more often and more comprehensively than did the designers working at conventional companies. This was particularly apparent in the discussions of raw materials; the designers working for DfE companies discussed fiber qualities with respect to sustainability and sustainability measures. These designers also conveyed a greater understanding of how decisions made during the design stage, such as how fiber content, may influence the human health and environmental impacts of interior textiles throughout the product life cycle.

One key finding from this study was that the application of sustainable design, development, and production methods, based upon consideration of potential impacts throughout the product life cycle, was present, but limited, owing to industry standards and regulation, demand for DfE products, availability of products, and production methods, and company size and resources. In addition, product performance and quality were, at times, perceived to be more important to achieve than reduced impacts to human health and the environment. This finding was consistent with the work of Handfield et al. (2001) in that the environmental impact of raw materials was viewed as less important than cost and availability.

Even though the human health and environmental impacts of interior textile products appeared to be important to all participants, it also was apparent that all of 
these designers worked within the limitations of their companies and the industry at large. The designer's perceived ability to attend to issues of sustainability at individual stages of the product life cycle was influenced by company size (i.e., amount of employees, resources), with participants working for larger companies were more likely to have separate departments to investigate particular points in the life cycle, such as addressing the end of use stage by implementing responsible return programs and having in house remanufacturing capabilities. Participants also expressed frustration in their inability to address issues at certain life cycle stages owing to company policy despite demonstrating personal knowledge of human health and environmental impacts, as exhibited in one participant's frustration of the overuse of plastic packaging for transport.

The designers' narratives revealed company engagement with and/or responsibilities toward stakeholders, primarily consumers, textile mills, and NGOs. Perceived responsibilities toward consumers were particularly apparent when addressing fabric finishes and treatments. To this end, some companies provided textiles with and without finishes to comply with consumer demand, and the designers who chose not to use performanceenhancing finishes expressed the need to educate consumers about the human health and environmental dangers of textile finishes. At times, engagement with stakeholders both supported and hindered company efforts toward creating sustainable interior textile products. For example, companies often rely on third-party organizations for textile testing in support of sustainable measures; however, existing limitations in testing may restrict overall efforts to improve upon sustainability. For instance, as one participant noted, GOTS does not provide a standard for hemp.

Engagement with and/or responsibilities toward stakeholders was in part influenced by the size of the company's financial resources and product demand. Because smaller DfE-oriented companies were producing less material, and therefore could not meet the higher minimum required by some mills, they had fewer choices with respect to mill and sourcing partnerships and less opportunity to engage in research and development. As a result, the consideration of human health and environmental impacts within the designer's decision-making tended to be influenced more by the limited selection of materials and manufacturing partners. Further, the designers employed at DfE-oriented companies appeared to place greater emphasis on relationships with stakeholders, including fiber producers, textile mills, and product printers, and the role that these entities play in minimizing the human health and environmental impacts of interior textile product than did the designers working at conventional companies.
Findings provide both theoretical and practical implications in regard to developing and/or implementing sustainable strategies to reduce human health and environmental impacts throughout the life cycle of interior textile products. First, findings provide support for stakeholder theory (Freeman 1984) in that participants in this study demonstrated a capacity to implement and/ or enhance sustainable methods to product design and development with the help of industry partners and attention to consumer demand and preferences. Further, participants noted their reliance upon outside groups, such as NGOs, to assist in holistic industry change, as demonstrated through calls for enhanced third-party standards, increased transparency, and enforced accountability to improve the current human health and environmental impacts of the textile industry. One general implication of this study is that interior textile designers possess considerable knowledge with respect to the human health and environmental issues related to product design, development, and production as well as increased understanding of the role that designers may play in mitigating the negative impacts of interior textiles throughout the product life cycle. Application of this knowledge and understanding to decision-making during the design process has the potential to provide economic and social benefits to companies and stakeholders alike. Another, more specific, implication is that designers and companies engaged in the development of interior textile products may enhance overall product sustainability by giving more attention to how decisions made during the design process impact human health and the environment at the later stages of the life cycle, especially the application stage of the life cycle.

One limitation of this study is the size of the sample; conclusions are based upon insights gained from only 12 designers of interior textile products. As such, findings from this study may not be representative of or generalizable to all designers/companies in the residential and/or commercial interior textile industry. A challenge to gathering data for the present study was gaining access to individuals or companies in the residential and/or commercial interior textile industry. The use of multiple sampling frames to identify participants was imperfect owing to the fact that a single, exhaustive list of US residential and/or commercial interior textile companies was not available. Also, no response from some companies and decision not to participate in the study owing to time constraints or lack of interest by other companies limited the size of the sample. A larger sample may have provided additional perspectives on the how decisions made during the design process for interior textiles may impact human health and the environment throughout the product life cycle and how these decisions may be influenced by an organization's 
engagement with and/or responsibilities toward its stakeholders. Another limitation of this study is that all of the findings are based upon self-reported data, most of which could not be independently verified and which may contain individual bias including selective memory and/or overstated knowledge/understanding. Also, as is the case with all qualitative research, the data represent participants' individual perspectives and experiences related to sustainable interior textile design, which may be unique to these individuals. Further, because the participants in this study acted as company representatives, some of their shared perspectives may reflect the company's policies and values rather than the participant's personal beliefs.

The findings from the present study provide suggestions for future research. For example, future studies may involve a broader and perhaps more diverse sample of companies, including non-US companies to provide a more comprehensive picture of the interior textile product industry's effort toward improved sustainability. Further, to gain more in-depth knowledge of designers' perspectives on if and how decisions made during the design process may impact human health and the environment throughout the product life cycle, researchers may wish to examine individual stages of the product life cycle separately, particularly the application stage, which appears to receive less attention during the design process.

\section{Additional file}

Additional file 1: Interview questions.

\section{Competing interests}

The authors declare that they have no competing interests.

\section{Authors' contributions}

SC conceptualized the study and carried out the data collection and analysis. $\mathrm{KH}$ contributed to the development of the theoretical framework, the development of the research method, and the interpretation of the data/ findings. Both SC and $\mathrm{KH}$ contributed to the writing of the manuscript. Both authors read and approved the final manuscript.

Received: 5 January 2016 Accepted: 21 May 2016

Published online: 07 July 2016

\section{References}

Abreu, M, Castro, F, Soares, F, \& Silva Filho, J (2012). A comparative understanding of corporate social responsibility of textile firms in Brazil and China. Journal of Cleaner Production, 20(1), 119-126. doi:10.1016/j.jclepro.2011.08.010.

Araji, MT, \& Shakour, SA (2013). Realizing the environmental impact of soft materials: criteria for utilization and design specification. Materials \& Design, 43, 560-571.

Behrendt, S, Jasch, C, Peneda, MC, \& van Weenen, H (1997). Life cycle design: a manual for small and medium-sized enterprises. Institut fur Zukunftsstudien und Technologiebewertung. Berlin: Springer.

Billatos, SB, \& Basaly, NA (1997). Green technology and design for the environment. Washington, D. C.: Taylor and Francis.
Birtwistle, G, \& Moore, CM (2007). Fashion clothing-where does it all end up? International Journal of Retail \& Distribution Management, 35(3), 210-216.

Bras, B (1997). Incorporating environmental issues in product design and realization. Industry and Environment, 20(1-2), 7-13.

Caniato, F, Caridi, M, Crippa, L, \& Moretto, A (2012). Environmental sustainability in fashion supply chains: an exploratory case based research. International Journal of Production Economics, 135(2), 659-670.

Carroll, AB (1991). The pyramid of corporate social responsibility: toward the moral management of organizational stakeholders. Business Horizons, 34(4), 39-48.

Chen, $\mathrm{H}-\mathrm{L}$, \& Burns, LD (2006). Environmental analysis of textile products. Clothing and Textiles Research Journal, 24(3), 248-261.

Chiu, MC, \& Chu, CH (2012). Review of sustainable product design from life cycle perspectives. International Journal of Precision Engineering and Manufacturing, 13(7), 1259-1272. doi:10.1007/s12541-012-0169-1.

Cobbing, M, \& Ruffinengo, E. (2013). Textiles: Stop the chemical overdose. Women in Europe for a Common Future. Retrieved from: http://www.wecf. eu/download/2013/ResizedReportWECFTextiles.pdf.

Coggon, D. (1996). Air pollution in homes. BMJ [British Medical Journal], 312(7042), 1316.

Daisey, JM, Angell, WJ, \& Apte, MG (2003). Indoor air quality, ventilation and health symptoms in schools: an analysis of existing information. Indoor Air, 13, 53-64.

Dev, V (2009). Carbon footprint of textiles. http://www.domain-b.com/ environment/20090403_carbon_footprint.html. Accessed 23 Feb 2016.

Dickson, MA, \& Eckman, M (2006). Social responsibility: the concept as defined by apparel and textile scholars. Clothing and Textiles Research Journal, 24(3), 178-191.

Environmental Design. (2013). Designtex. http://blog.designtex.com/2012/01/ whats-good-2012.html. Accessed 25 Jul 2015

Fiksel, J (1996). Design for environment: creating eco-efficient products and processes (pp. 473-490). New York: McGrawp-Hill.

Freeman, RE (1984). Strategic management: a stakeholder approach. Marshfield, MA: Pitman Publishing.

Fuad-Luke, A (2002). The eco-design handbook: a complete sourcebook for the home and office. London: Thames and Hudson.

Fuad-Luke, A (2009). Design activism: beautiful strangeness for a sustainable world. London: Earthscan.

Gam, HJ, \& Banning, J (2011). Addressing sustainable apparel design challenges with problem-based learning. Clothing and Textiles Research Journal, 29(3), 202-215.

Gam, HJ, Cao, H, Farr, C, \& Heine, L (2009). C2CDA: a sustainable apparel and design production model. International Journal of Clothing Science and Technology, 21(4), 166-179.

Gam, HJ, Cao, H, Bennett, J, Helmkamp, C, \& Farr, C (2011). Application of design for disassembly in men's jacket: a study on sustainable apparel design. International Journal of Clothing Science and Technology, 23(2), 83-94.

Giudice, F, La Rosa, G, \& Risitano, A (2005). Materials selection in the life-cycle design process: a method to integrate mechanical and environmental performances in optimal choice. Materials and Design, 26(1), 9-20. doi:10. 1016/j.matdes.2004.04.006.

Glaser, BG, \& Strauss, AL (1967). The discovery of grounded theory: strategies for qualitative research. Chicago: Aldie.

Glesne, C. (2011). Becoming qualitative researchers: an introduction (4th ed.). Boston: Pearson.

Goldbach, M, Seuring, S, \& Back, S (2003). Co-ordinating sustainable cotton chains for the mass market. Greener Management International, 43, 65-78.

Graedel, TE, \& Allenby, BR (1996). Design for environment. Upper Saddle River, NJ: Prentice Hall.

Guetzkow, H (1950). Unitizing and categorizing problems in coding qualitative data. Journal of Clinical Psychology, 6(10), 47-58.

Handfield, RB, Melnyk, SA, Calantone, RJ, \& Curkovic, S (2001). Integrating environmental concern into the design process: the gap between theory and practice. IEEE Transactions on Engineering Management, 48(2), 189-208.

$\mathrm{Hu}, \mathrm{Y}$ (2012). A study on the sustainable fashion design in the process of use. International Journal of Arts and Commerce, 1(4), 54-59.

Ip, K, Miller, A \& Ellis, J (2003). Criteria and measurement of indoor air quality in sustainable buildings. In D. G. Greenwood (Ed.), 19th Annual ARCOM 
Conference (Association of Researchers in Construction Management, Vol. 1, pp. 91-100). Brighton, UK: University of Brighton.

Jaakkola, JK, Øie, L, Nafstad, P, Botten, G, Sammelsen, S, \& Magnus, P (1999). Interior surface materials in the home and the development of bronchial obstruction in young children in Oslo, Norway. American Journal of Public Health, 89(2), 188-192.

Jackson, J (2014). Assessing the environmental impact of the fashion world. Environmental Leader. http://www.environmentalleader.com/2014/10/06/ assessing-the-environmental-impact-of-the-fashion-world/. Accessed 25 Jul 2015.

Joergens, C (2006). Ethical fashion: myth or future trend. Journal of Fashion Marketing and Management, 10(3), 360-71.

Joy, A, Sherry, JF, Venkatesh, A, Wang, J, \& Chan, R (2012). Fast fashion, sustainability, and the ethical appeal of luxury brands. Fashion Theory, 16(3), 273-296.

Kamide, H, Yamamoto, T, Nakahira, T, Watanabe, H, \& Oka, T (2013). Enrichment of design for environment (DFE) and development of its support system. FUJITSU TEN Technical Journal, 38, 21-25.

Keoleian, G, \& Menery, D (1993). Life-cycle design guidance manual. (EPA Publication No. EPA 600/R-92/226). Washington, D.C: U.S. Government Publishing Office.

Kim, B (2010). Green design: studies about fashion handbag. In 2010 IEEE 11th international conference on computer-aided industrial design \& conceptual design (CAIDCD) vol.2, (pp. 815-819). doi:10.1109/CAIDCD.2010.5681896.

Laitala, K, \& Boks, C (2012). Sustainable clothing design: use matters. Journal of Design Research, 10(1/2), 121-139.

Laitala, K, Boks, C, \& Klepp, IG (2011). Potential for environmental improvement in laundering. International Journal of Consumer Studies, 35(2), 254-264. doi:10. 1111/j.1470-6431.2010.00968.x.

Leal-Yepes, AM (2013). Evaluating the effectiveness of design for the environment tools to help meet sustainability and design goals thesis. Rochester Institute of Technology. http://scholarworks.rit.edu/cgi/viewcontent. cgi?article $=1938 \&$ context=theses. Accessed 18 Feb 2016

Levi Strauss \& Co (2015). The life cycle of a jean: understanding the environmental impact of a pair of Levi's 501 jeans. http://levistrauss.com/ wp-content/uploads/2015/03/Full-LCA-Results-Deck-FINAL.pdf. Accessed 25 Jul 2015

Lu, S (2015). Market size of the global textile and apparel industry: 2014 to 2018. https://shenglufashion.wordpress.com/2015/08/09/market-size-ofthe-global-textile-and-apparel-industry-2014-to-2018/. Accessed 23 Feb 2016

Mace, MA (1997). Toward an understanding of creativity through a qualitative appraisal of contemporary art making. Creativity Research Journal, 10(2-3), 265-278.

Mackenzie, D (1991). Design for the environment. New York: Rizzolli.

McDonough, W., \& Braungart, M. (2002). Cradle to cradle: remaking the way we make things. New York, New York: North Point Press.

Muthu, SS, Li, YY, Hu, JY, \& Mok, PY (2012). Quantification of environmental impact and ecological sustainability for textile fibres. Ecological Indicators, 13(1), 66-74. doi:10.1016/j.ecolind.2011.05.008.

Nanotechnology textiles. (2010). Nanowerk. http://www.nanowerk.com/spotlight/ spotid=19451.php. Accessed 14 Feb 2016.

Niinimäki, K, \& Hassi, L (2011). Emerging design strategies in sustainable production and consumption of textiles and clothing. Journal of Cleaner Production, 19(16), 1883-1846. doi:10.1016/j.jclepro.2011.04.020

Niinimäki, K (2006). Ecodesign and textiles. Research Journal of Textiles and Apparel, 10(3), 67-75.

Niinimäki, K (2015). Ethical foundation in sustainable fashion. Textiles and Clothing Sustainability, 1, 3. doi:10.1186/s40689-015-0002-1.

Oecotextiles (2009). Carbon footprint of the textile industry. https://oecotextiles. wordpress.com/2009/05/25/carbon-footprint-of-the-textile-industry/. Accessed 23 Feb 2016.

Pahl, G, \& Beitz, W (1988). In K. Wallace (Ed.), Engineering design: a systematic approach. London: The Design Council.

Pammi, S, Geetha, D, Danford, M, \& Charles, K (2012). Creating a global vision for sustainable fashion. In Textiles: A global vision-Textiles Institute Centenary World Conference (pp. 247-275). Manchester: Pakistan Textile Journal.

Papanek, VJ (1995). The green imperative. New York: Thames and Hudson.
Preisser, AM, Budnik, LT, \& Baur, X (2012). Health effects due to fumigated freight containers and goods: how to detect, how to act. International Maritime Health, 63(3), 133-139.

Ramani, K, Ramanujan, D, Bernstein, WZ, Zhao, F, Sutherland, J, \& Handwerker, C (2010). Integrated sustainable life cycle design: a review. Journal of Mechanical Design, 132, 1-15.

Rastogi, N (2009). The eco-perils of cheap décor: is fake wood furniture bad for the environment? Slate.com. http://www.slate.com/articles/health_and_science/ the_green_lantern/2009/09/the_ecoperils_of_cheap_decor.html. Accessed 25 Jul 2015.

Rivera, JL, Seely, B, \& Sutherland, JW (2012). Societal implications of nanotechnology: occupational perspectives. Environment, Development and Sustainability, 14(5), 807-825.

Saxce, M, Pesnel, S, \& Perwuelz, A (2012). LCA of bed sheets-some relevant parameters for lifetime assessment. Journal of Cleaner Production, 37, 221-228. doi:10.1016/j.jclepro.2012.07.012.

Shank, GD (2002). Qualitative research: a personal skills approach. Upper Saddle River, NJ: Merrill Prentice Hall.

Stegall, N (2006). Designing for sustainability: a philosophy for ecologically intentional design. Design Issues, 22(2), 56-63.

Strauss, A, \& Corbin, J (1998). Basics of qualitative research (2nd ed.). Thousand Oaks, CA: Sage Publications.

Sun, J, Han, B, Ekwaro-Osire, S, \& Zhang, H (2003). Design for environment: methodologies, tools, and implementation. Journal of Integrated Design and Process Science, 7(1), 59-75.

Thiry, MC (2005). Every shirt has a story. AATCC Review, 3(5), 7-12.

Tremblay, KR, Peng, L-W, Kreul-Froseth, SA, \& Dunbar, BH (1999). Perceived effects of carpet on indoor air quality. Housing and Society, 23(1), 16-25.

U.S. Environmental Protection Agency (2013). Fast facts: US transportation sector greenhouse gas emissions 1990-2011. Office of Transportation and Air Quality, EPA-420-F-13-033a. http://www.epa.gov/otaq/dlimate/documents/420f13033a. pdf. Accessed 25 Jul 2015.

U.S. Environmental Protection Agency (2015). Advancing Sustainable Materials Management: Facts and Figures 2013. https://www.epa.gov/sites/production/ files/2015-09/documents/2013_advncng_smm_rpt.pdf. Accessed 25 May 2016.

Uhdea, E, \& Salthammer, T (2007). Impact of reaction products from building materials and furnishings on indoor air quality - a review of recent advances in indoor chemistry. Atmospheric Environment, $41(15), 3111-3128$

Whiteley, N (1987). Toward a throw-away culture. Consumerism, 'style obsolescence' and cultural theory in the 1950s and 1960s. Oxford Art Journal, $10(2), 3-27$.

Whitehead, S (2014). 6 things you should know about your clothing. Huffington Post. http://www.huffingtonpost.com/shannon-whitehead/clothingglobalization_b_4733516.html. Accessed 23 Feb 2016.

Woolridge, AC, Ward, GD, Phillips, PS, Collins, M, \& Gandy, M (2006). Life cycle assessment for reuse/recycling of donated waste textiles compared to use of virgin material: an UK energy saving perspective. Resources, Conservation and Recycling, 46(1), 94-103.

Wright, HE, Zhang, Q, \& Mihelcic, JR (2008). Integration economic inputoutput life cycle assessment with risk assessment for a screening-level analysis. International Journal of Life Cycle Assessment, 13(5), 412-420. doi:10.1007/s11367-008-0006-z.

Yang, Q, Yu, S, \& Sekhari, A (2011). A modular eco-design method for life cycle engineering based on redesign risk control. International Journal of Advanced Manufacturing Technology, 56(9), 1215-1233. doi:10.1007/s00170-011-3246-1.

Zakhem, AJ, Palmer, DE, \& Stoll, ML (2008). Stakeholder theory. Amherst, NY: Prometheus Books. 